\title{
ATRIBUTOS FÍSICOS DE CAMBISSOLO HÁPLICO EM VINHEDOS SUBMETIDOS A INTENSIDADES DE TRÁFEGO ${ }^{(1)}$
}

\author{
Cassio Marques de Valois ${ }^{(2)}$, Jucinei José Comin ${ }^{(3)}$, Milton da Veiga ${ }^{(4)}$, Gustavo \\ Brunetto $^{(5)}$, Jamil Abdalla Fayad ${ }^{(6)}$, Fernando Cesar Bauer ${ }^{(7)}$, Arcângelo Loss ${ }^{(7)}$, Marcel \\ Pires de Moraes ${ }^{(8)}$ \& Cleiton Junior Ribeiro Lazzari ${ }^{(8)}$
}

\section{RESUMO}

Em vinhedos, o tráfego de máquinas agrícolas causa compactação do solo que pode ser mais acentuada nas entrelinhas pela maior intensidade de tráfego. Este trabalho objetivou avaliar a variabilidade dos atributos físicos do solo em razão da posição de amostragem em relação à linha de plantio, em vinhedos comerciais da variedade Bordô em pé franco, submetidos a diferentes manejos da cultura. Em fevereiro de 2012, três vinhedos foram selecionados no município de Major Gercino (SC), sendo um manejado sem a utilização de máquinas agrícolas (vinhedo 1: com seis anos de implantação) e dois que utilizam máquinas nas entrelinhas (vinhedos 2 e 3: com oito e 17 anos, respectivamente). Na linha de plantio (Lp), na linha do rodado (Lr) e entre a linha de plantio e a linha do rodado (El), foram coletadas amostras indeformadas de solo nas camadas de 0,00-0,05, 0,05-0,10, 0,10-0,15 e 0,15-0,20 m de profundidade. Avaliaram-se a densidade do solo (Ds), a resistência à penetração $(\mathrm{Rp})$, as classes de poros (macroporos - MaP, mesoporos - MeP, microporos - MiP e porosidade total - PT), os índices de agregação e de estabilidade de agregados (Diâmetro médio geométrico dos agregados secos ao ar e estáveis em água - DMGsa e DMGea, índice de estabilidade de agregados - IEA), a umidade gravimétrica (Ug), a densidade das partículas e a granulometria do solo. $\mathrm{O}$ estado

(1) Parte da Dissertação de Mestrado do primeiro autor. Recebido para publicação em 25 de junho de 2013 e aprovado em 19 de maio de 2014.

(2) Mestrando do Programa de Pós-Graduação em Agroecossistemas - PGA, Centro de Ciências Agrárias - CCA, Universidade Federal de Santa Catarina - UFSC. Campus Universitário Reitor João David Ferreira Lima Trindade, Bairro Itacorubi. CEP 88040-900 Florianópolis (SC). Bolsista da CAPES. E-mail: cassiovalois@gmail.com

(3) Professor Associado VI, Departamento de Engenharia Rural (ENR), CCA, UFSC. Rodovia Admar Gonzaga, 1346, Bairro Itacorubi. CEP 888034-000 Florianópolis (SC). E-mail: jcomin@cca.ufsc.br

(4) Pesquisador, Estação Experimental da Empresa de Pesquisa Agropecuária e Extensão Rural de Santa Catarina (EPAGRI). BR 282, km 342. Caixa Postal 116. CEP 89620-000 Campos Novos (SC). E-mail: milveiga@epagri.sc.gov.br

(5) Professor Adjunto II, Departamento de Solos, Centro de Ciências Rurais, Universidade Federal de Santa Maria. Av. Roraima, 1000, Bairro Camobi. CEP 97105-900 Santa Maria (RS). E-mail: brunetto.gustavo@gmail.com

(6) Extensionista, EPAGRI Regional da Grande Florianópolis. Caixa Postal 502. CEP 88.034-901 Florianópolis (SC). E-mail: jamil@epagri.sc.gov.br

(7) Professor Adjunto, ENR, CCA, UFSC. E-mail: febauer@cca.ufsc.br, arcangelo.loss@ufsc.br

(8) Acadêmico do Curso de Agronomia, ENR, CCA, UFSC. E-mail: marcelpmoraes@gmail.com, cleitonlazzari@yahoo.com.br 
de compactação aumentou no sentido da Lp para a Lr. A ocorrência de tráfego, em geral, influenciou negativamente os atributos avaliados. Entre as posições de amostragem, os maiores valores de Ds e Rp ocorreram na Lr, em que a Rp atingiu valores críticos ao desenvolvimento de raízes; nos vinhedos mecanizados, foram encontrados elevados valores de $\mathrm{Rp}$ e baixos de MaP nas camadas de 0,00-0,05 e 0,05-0,10 m. Observaram-se agregados com maior diâmetro e menores IEA, o que indica deterioração da qualidade física do solo. No vinhedo 1 , houve menor variabilidade dos atributos físicos, enquanto no vinhedo 2 verificou-se influência negativa do tráfego de máquinas, principalmente para os atributos relacionados à agregação e elevada MiP. No vinhedo 3, observaram-se os maiores índices de Rp e de Ds, bem como o menor valor de MaP. Portanto, em relação aos vinhedos estudados, verificou-se aumento da degradação física do solo proporcionado pelo tráfego de máquinas (vinhedos 2 e 3). Dentre as posições de coletas e os vinhedos, evidenciou-se, por meio da análise de componentes principais, a separação da posição Lr do vinhedo 3, em razão dos atributos Ds e Rp, permitindo inferir que o manejo adotado na posição Lr está ocasionando maior degradação da qualidade física do solo.

Termos de indexação: variabilidade de atributos físicos do solo, Vitis labrusca, análise de componentes principais.

\section{SUMMARY: PHYSICAL ATTRIBUTES OF A HAPLIC CAMBISOL IN VINEYARDS SUBJECTED TO DIFFERENT TRAFFIC INTENSITIES}

Agricultural machine traffic causes soil compaction in vineyards, which may be accentuated between the rows due to greater intensity of traffic. The aim of this study was to evaluate the variability of soil physical properties as a function of the sampling position in relation to the plant row in commercial vineyards of the Bordo variety planted directly in the soil and subjected to different management practices. In February 2012, three vineyards were selected in the municipality of Major Gercino, southern Brazil - one without the use of agricultural machinery (vineyard 1 with six years of age) and two that use machines between the rows (vineyards 2 and 3 , with eight and 17 years of age, respectively). Undisturbed soil samples were collected in the crop row (Cr), the wheel row (Wr), and between the crop row and the wheel row (Br) at the 0.00-0.05, 0.05-0.10, 0.10-0.15, and 0.15-0.20 m depths. We evaluated bulk density $(B d)$, resistance to penetration (Rp), pore classes (macropores - MaP, mesopores - MeP, micropores - MiP, and total porosity - TP), aggregation and aggregate stability indices (mean geometric diameter of air-dried aggregates - MGDad, and water stable aggregates - MGDws, and aggregate stability index - ASI), gravimetric moisture (Gm), and particle density and particle size distribution in the soil. Compaction increased in the direction from the Cr to the Wr. The occurrence of traffic, in general, negatively affected the properties evaluated. Among the sampling positions, the greatest values of Bd and Rp occurred in the $W r$, where the Rp reached critical values for root development. In the mechanized vineyards, high values of Rp and low values of $\mathrm{MaP}$ were found in the 0.00-0.05 and 0.05-0.10 m layers. Aggregates of greater diameter and the lowest ASI were also found, which indicates deterioration of soil physical quality. In vineyard 1, there was less variability of the physical properties; while in vineyard 2 the negative effect of machine traffic was observed, especially for the properties related to aggregation and high MiP. In vineyard 3, greater indices of $R p$ and $B d$ were observed, as well as the lowest value of MaP. Therefore, in relation to the vineyards studied, an increase in soil physical degradation was caused by machine traffic (vineyards 2 and 3). Among the soil collection positions and the vineyards, separation of the Wr position of vineyard 3 was seen by means of principal component analysis, stemming from the $B d$ and Rp properties, from which it may be inferred that the management adopted in the Wr position of vineyard 3 is leading to greater degradation of soil physical quality.

Index terms: variability of soil physical properties, Vitis labrusca, principal component analysis. 


\section{INTRODUÇÃO}

O Estado de Santa Catarina possui a quinta maior área cultivada com videira do Brasil, destacando-se a região do Vale do Rio Tijucas como uma das principais regiões vitivinícolas. Cultivam-se videiras americanas (Vitis labrusca), e as uvas são destinadas à elaboração de sucos e vinhos de mesa. Os vinhedos são instalados, predominantemente, em Cambissolos localizados em relevo plano a suave ondulado.

Anualmente, por causa da elevada e constante umidade relativa do ar e altas temperaturas, especialmente durante o período vegetativo e reprodutivo, as videiras são submetidas a contínuas aplicações de fungicidas para o controle preventivo de doenças fúngicas foliares. As aplicações são realizadas usandose máquinas e equipamentos agrícolas, como tratores e pulverizadores, que trafegam nas entrelinhas dos vinhedos, inclusive quando o solo possui teor de água acima da capacidade de campo. Isso causa a aproximação das partículas do solo pela pressão dos rodados e, consequentemente, pode provocar a compactação do solo nas entrelinhas (van Dijck \& van Asch, 2002; Lima et al., 2004; Rosa et al., 2009; Braida et al., 2011).

A compactação do solo em entrelinhas de vinhedos (van Dijck \& van Asch, 2002; Ferrero et al., 2005), citrus (Lima et al., 2004) e pereira (Vocanson et al., 2006) pode modificar os atributos físicos do solo, como a densidade do solo, a resistência à penetração, a porosidade, a estabilidade de agregados, a estrutura e o grau de floculação das argilas (Silva et al., 2006; Echenique et al., 2007; Portugal et al., 2008; Rosa et al., 2009), comparativamente aos atributos físicos na linha de plantio dos pomares onde não é realizado o tráfego. Entretanto, a modificação dos atributos depende da intensidade do tráfego a que o solo é submetido (Lima et al., 2004; Elaoud \& Chehaibi, 2011). Essas alterações reduzem o suprimento de oxigênio e promovem restrições físicas ao crescimento das raízes das plantas, diminuindo o volume de solo explorado e, por consequência, podem reduzir a quantidade de água e nutrientes absorvidos, refletindo negativamente na taxa fotossintética, no crescimento e no rendimento das culturas (De Maria et al., 1999; Beutler \& Centurion, 2004; Beutler et al., 2006; Fidalski et al., 2010; Costa et al., 2012; Luciano, 2012).

Valores de densidade (Ds) em solos arenosos considerados normais estão compreendidos entre 1,20 e $1,90 \mathrm{~kg} \mathrm{dm}^{-3}$; o valor médio para solos compactados que redunda em restrição ao crescimento radicular (Ds crítica) encontra-se na faixa de $1,65 \mathrm{~kg} \mathrm{dm}^{-3}$ (Reinert \& Reichert, 2006). Já o valor proposto por Reichert et al. (2003) de Ds crítica para solos com textura média (20 a $55 \%$ de argila) foi de $1,55 \mathrm{~kg} \mathrm{dm}^{-3}$. Como a porosidade total é inversamente proporcional à densidade do solo, e a macroporosidade é a maior responsável pela aeração do solo e drenagem interna do perfil, é necessário que essa esteja numa faixa mínima de $10 \%$ para suprir a demanda de oxigênio no solo (Xu et al., 1992).
Para diversas culturas, os valores de resistência à penetração $(\mathrm{Rp})$ acima dos 2,0 MPa são considerados limitantes para o crescimento das raízes (Taylor et al., 1966; Nesmith, 1987). Para a cultura da videira, em solos com horizontes muito coesos até $0,35 \mathrm{~m}$ de profundidade, onde os valores de Rp ultrapassam os 3,0 MPa, Echenique et al. (2007) verificaram redução no rendimento, na área foliar e na massa de material podado da videira. Em geral, o aumento da Rp tem sido verificado em solos cultivados em razão do tráfego de máquinas agrícolas, onde há tendência de aumento da $\mathrm{Rp}$ com o aumento da intensidade do tráfego (Elaoud \& Chehaibi, 2011). Além disso, a Rp também é utilizada para comparar diferentes manejos e locais em sistemas de produção, evidenciando a degradação física de solos submetidos à aplicação de pressão na superfície pelo tráfego de máquinas, como o caso de compactação de pomares (Echenique et al., 2007; Portugal et al., 2008; 2010), reflorestamento (Seixas \& Souza, 2007) e culturas anuais (Fuentes Llanillo et al., 2006; Andrade et al., 2010), sendo também associada a um menor crescimento radicular (Costa et al., 2012).

No Brasil, a maioria dos estudos que abordam a compactação e problemas estruturais de solo trata de culturas anuais e solos que são revolvidos anualmente, enquanto poucos trabalhos relatam situações de solos não revolvidos sob culturas perenes (Reichert et al., 2007), como é o caso dos vinhedos. Esses autores consideram que, para uma avaliação confiável e que possibilite a inferência sobre a qualidade física do solo, é necessário determinar vários atributos físicos e interpretá-los em conjunto para evitar uma avaliação errônea do estado de compactação de determinado solo.

Considerando a constante utilização de tráfego de máquinas agrícolas nas entrelinhas dos vinhedos instalados em Cambissolos, que é uma das classes de maior ocorrência em SC (Embrapa, 1998), este trabalho objetivou avaliar a variabilidade dos atributos físicos do solo em razão da posição de amostragem em relação à linha de plantio, em três vinhedos comerciais da variedade Bordô em pé franco, submetidos a diferentes manejos.

\section{MATERIAL E MÉTODOS}

Este trabalho foi realizado em 2012 em três vinhedos comerciais, no município de Major Gercino, situado no Alto Vale do Rio Tijucas, SC, nas coordenadas geográficas $27^{\circ} 26^{\prime} 42^{\prime \prime}$ sul e $49^{\circ} 06^{\prime} 27^{\prime \prime}$ oeste (Vinhedo 1 - 1,5 ha), $27^{\circ} 25^{\prime} 16^{\prime \prime}$ sul e $49^{\circ} 04^{\prime} 31^{\prime \prime}$ oeste (Vinhedo 2 - 6 ha), $27^{\circ} 25^{\prime} 18^{\prime \prime}$ sul e $49^{\circ} 05^{\prime} 53^{\prime \prime}$ oeste (Vinhedo 3 - 3,4 ha), com altitudes de 530 a $545 \mathrm{~m}$ e distância entre os vinhedos de 1,5 e $2,5 \mathrm{~km}$. O clima do local é temperado úmido, com verões quentes e sem estação seca definida, do tipo Cfa, de acordo com a classificação de Köppen, com 
temperatura média anual de $20{ }^{\circ} \mathrm{C}$ e precipitação pluvial entre 1.500 e $1.700 \mathrm{~mm}$ bem distribuída ao longo do ano (Pandolfo et al., 2002). Os solos dos vinhedos foram classificados como Cambissolo Háplico Tb eutrófico típico, textura média, pouco cascalhento a cascalhento, A moderado, relevo plano, substrato sedimentos recentes de Granito da Suíte Valsungana (Embrapa, 2006). Os atributos químicos determinados em amostras de solo coletadas em cada vinhedo na camada de 0,00-0,20 m são apresentados no quadro 1 .

Os vinhedos foram compostos pela variedade Bordô (Vitis labrusca) em pé franco, implantados nos anos de 2006, 2004 e 1995 (Vinhedos 1, 2 e 3, respectivamente). Anteriormente à implantação desses, as áreas eram cultivadas com fumo (Nicotiana tabacum) em sistema de manejo com revolvimento intensivo do solo (aração e gradagem) e uso constante de agrotóxicos e adubações com fertilizantes de síntese química, o que explica a característica de epieutrofismo desses solos (Quadro 1), que originalmente eram classificados como álicos (Embrapa, 1998).

O sistema de condução utilizado nos três vinhedos é do tipo latada, com espaçamento de $3 \mathrm{~m}$ entre fileiras e $2 \mathrm{~m}$ entre plantas. Em todos os vinhedos, foram semeadas a lanço, sem incorporação, aveia-preta (Avena strigosa) e ervilhaca (Vicia sativa), sendo roçadas quatro vezes por ano; e a matéria seca foi depositada na superfície do solo.

No vinhedo 1, considerada área-controle, não foi utilizado maquinário agrícola e todas as práticas de manejo foram realizadas manualmente. O tráfego de máquinas ocorreu externamente ao vinhedo. No vinhedo 2 , o tráfego foi realizado 20 vezes por ano,

Quadro 1. Atributos químicos e físicos do solo, na camada de 0,00-0,20 m, em Cambissolo Háplico em três vinhedos

\begin{tabular}{|c|c|c|c|}
\hline Atributo $^{(1)}$ & Vinhedo 1 & Vinhedo 2 & Vinhedo 3 \\
\hline Matéria orgânica $\left(\mathrm{g} \mathrm{kg}^{-1}\right)$ & 22 & 22 & 31 \\
\hline $\mathrm{pH}\left(\mathrm{H}_{2} \mathrm{O}\right)$ & 5,3 & 6,2 & 5,9 \\
\hline Índice SMP & 5,9 & 6,5 & 6,4 \\
\hline $\mathrm{P}\left(\mathrm{mg} \mathrm{dm}^{-3}\right)^{(2)}$ & 29,1 & 62,9 & 21,9 \\
\hline $\left.\mathrm{K}(\mathrm{mg} \mathrm{dm})^{-3}\right)^{(2)}$ & 172,0 & 242,0 & 176,0 \\
\hline $\mathrm{Al}^{3+}\left(\mathrm{cmol}_{\mathrm{c}} \mathrm{dm}^{-3}\right)^{(3)}$ & 1,1 & 0,0 & 0,0 \\
\hline $\mathrm{Ca}^{2+}\left(\mathrm{cmol}_{\mathrm{c}} \mathrm{dm}^{-3}\right)^{(3)}$ & 3,9 & 5,6 & 4,6 \\
\hline $\mathrm{Mg}^{2+}\left(\mathrm{cmol}_{\mathrm{c}} \mathrm{dm}^{-3}\right)^{(3)}$ & 2,3 & 2,9 & 3,2 \\
\hline $\mathrm{CTC}_{\mathrm{pH} 7,0}\left(\mathrm{cmol}_{\mathrm{c}} \mathrm{dm}^{-3}\right)^{(3)}$ & 11,5 & 11,6 & 11,0 \\
\hline Saturação por bases (\%) & 57,6 & 78,8 & 75,0 \\
\hline Saturação por Al (\%) & 14,2 & 0,0 & 0,0 \\
\hline Argila $\left(\mathrm{g} \mathrm{kg}^{-1}\right)^{(4)}$ & 199,0 & 282,0 & 284,0 \\
\hline Silte $\left(\mathrm{g} \mathrm{kg}^{-1}\right)^{(4)}$ & 199,0 & 417,0 & 268,0 \\
\hline Areia $\left(\mathrm{g} \mathrm{kg}^{-1}\right)^{(4)}$ & 602,0 & 301,0 & 448,0 \\
\hline $\operatorname{Dp}\left(\mathrm{kg} \mathrm{dm}^{-3}\right)^{(4)}$ & 2,54 & 2,47 & 2,62 \\
\hline
\end{tabular}

(1) Determinados segundo Tedesco et al. (1995); ${ }^{(2)}$ extraído por Mehlich-1; ${ }^{(3)}$ extraído por $\mathrm{KCl} 1 \mathrm{~mol} \mathrm{~L}^{-1}$; e ${ }^{(4)}$ densidade das partículas, determinado conforme Veiga (2011). com um trator marca Tramontini ${ }^{\circledR} 4 \times 2$ modelo T3025-4 (950 kg de massa total, rodado dianteiro 6" $\times$ 12 " e traseiro 9.5 " × 24 ", com pressão de inflação de 25 e $40 \mathrm{lb}$, respectivamente), com taxa de compressão estimada de $0,387 \mathrm{~kg} \mathrm{~cm}^{-2}$ (Mialhe, 1980). Já no vinhedo 3, o tráfego foi realizado 30 vezes por ano com um trator de rabiças marca Yanmar ${ }^{\circledR}$ modelo Cultivador Motorizado TC14 Super (433 kg de massa total, rodado 6 " × 12 " com pressão de inflação de $25 \mathrm{lb}$ ), com taxa de compressão estimada de $0,928 \mathrm{~kg} \mathrm{~cm}^{-2}$. Utilizou-se um pulverizador de turbina com capacidade para $300 \mathrm{~L}$, nos vinhedos 2 e 3.

Para determinação dos atributos físicos do solo, foram coletadas amostras com estrutura preservada utilizando-se anéis volumétricos de aço inox com $0,05 \mathrm{~m}$ de altura e $0,07 \mathrm{~m}$ de diâmetro interno. As coletas foram realizadas em quatro camadas $(0,00-0,05$, 0,05-0,10, 0,10-0,15 e 0,15-0,20 m de profundidade) e em três locais distintos nos vinhedos: na linha de plantio (Lp); na linha do rodado (Lr); e entre a linha do rodado e a linha de plantio (El), com três repetições por local de coleta. As amostras foram coletadas em três subparcelas homogêneas dos vinhedos com a seleção do local de coleta feita aleatoriamente com o uso de um marcador lançado em cada uma delas. Os pontos de coleta se distanciaram aproximadamente $40 \mathrm{~m}$ entre si.

Depois de realizada a limpeza e preparação das amostras, utilizaram-se os métodos de rotina para a determinação dos atributos físicos do solo descritos em Veiga (2011). Para calcular o volume de água retida nas classes de poros e a densidade do solo (Ds), foi determinada a massa das amostras após sua saturação por capilaridade e, sequencialmente, após aplicadas tensões de $6 \mathrm{kPa}$ (box de areia) e $600 \mathrm{kPa}$ (Extrator de Richards), bem como após efetuada a secagem em estufa a $105^{\circ} \mathrm{C}$, nesse caso, de uma fração da amostra até massa constante. A Ds $\left(\mathrm{kg} \mathrm{dm}^{-3}\right)$ corresponde à relação entre a massa de solo seco em estufa e o volume interno do respectivo anel volumétrico. $\mathrm{O}$ volume total de poros $(\mathrm{PT})$, macro (MaP, poros com $\varnothing>50 \mu \mathrm{m})$, meso (MeP, poros com $\varnothing$ entre 50-0,5 $\mu \mathrm{m}$ ) e microporos (MiP, poros com $\varnothing<0,5 \mu \mathrm{m})$ correspondem, respectivamente, à relação entre o volume de água retido no solo após sua saturação, entre a saturação e a tensão de $6 \mathrm{kPa}$, entre as tensões de 6 e $600 \mathrm{kPa}$ e com umidade equilibrada na tensão de $600 \mathrm{kPa}$, todos calculados em relação ao volume interno do respectivo anel volumétrico.

A resistência do solo à penetração foi determinada em laboratório no centro das mesmas amostras utilizadas para discriminar a porosidade e Ds, após estabilização da umidade na tensão de $600 \mathrm{kPa}$. Para essa determinação, foi utilizado um penetrômetro de bancada marca Marconi, modelo MA933, equipado com pino de penetração de $80 \mathrm{~mm}$ de altura e ponta cônica angular de $30^{\circ}$, ajustado para velocidade de penetração de $1,0 \mathrm{~mm} \mathrm{~s}^{-1}$ e registros em intervalos de $1,0 \mathrm{~mm}$. O valor para cada amostra correspondeu à 
média dos 30 valores obtidos entre 11 e $40 \mathrm{~mm}$ de profundidade. Feita a leitura no penetrômetro, foi pesado aproximadamente $20 \mathrm{~g}$ do solo para determinar o fator de correção da umidade gravimétrica (Ug) na tensão de $600 \mathrm{kPa}$ para solo seco.

Após definida a $R p$, iniciou-se a análise de distribuição de tamanhos e estabilidades dos agregados, em que foram analisados os agregados secos ao ar e estáveis em água. O solo utilizado foi retirado dos anéis e cuidadosamente destorroado, separandose os agregados nos planos de fraqueza, até que toda a amostra passasse pela peneira com abertura de malha de $8 \mathrm{~mm}$. As amostras foram secas ao ar livre e à sombra por uma semana.

Para se determinar a distribuição de tamanho dos agregados secos ao ar, foram pesados de 25 a $30 \mathrm{~g}$ da amostra e, em seguida, colocadas na sequência de peneiras com $20 \mathrm{~cm}$ de diâmetro e $5 \mathrm{~cm}$ de altura, com aberturas de malha de 4,00;2,00;1,00;0,50 mm; e fundo, sequencialmente. Com a amostra nas peneiras, foram realizados 12 movimentos de ida e vinda em um sentido, girado o conjunto em $90^{\circ} \mathrm{e}$ repetidos os movimentos, com a posterior pesagem do material retido em cada peneira e no fundo, calculandose o diâmetro médio geométrico de agregados secos ao ar (DMGsa).

Essa amostra utilizada foi recomposta, com a exclusão do material retido no fundo para determinar a estabilidade dos agregados em água. Para essa definição foi utilizada a mesma sequência de peneiras acopladas a um oscilador mecânico, com amplitude de oscilação de aproximadamente $4 \mathrm{~cm}$ e frequência de oscilação de 30 ciclos min $^{-1}$ dentro de recipiente com água, similar ao aparelho de Yoder. As amostras foram acondicionadas no fundo da primeira peneira e ficaram em descanso por $10 \mathrm{~min}$ (umedecendo). Decorrido esse tempo, foi iniciada, por mais $10 \mathrm{~min}$, a agitação das peneiras para separação do material e, em seguida, o solo retido nas diferentes peneiras foi seco em estufa a $105^{\circ} \mathrm{C}$, calculando-se o diâmetro médio geométrico de agregados estáveis em água (DMGea). De posse desses valores, foi realizado o cálculo do índice de estabilidade de agregados (IEA) pela fórmula IEA = DMGea/DMGsa.

A densidade das partículas (Dp) foi determinada utilizando-se o método do balão volumétrico e álcool, sendo os cálculos em base de massa (Gubiani et al., 2006). A granulometria foi discriminada pelo método da pipeta, adaptado por Veiga (2011) para análise de rotina.

Os dados provenientes das análises físicas do solo foram avaliados quanto à homocedastia, pelo teste de Cochran (Snedecor \& Cochran, 1989) e distribuição normal dos resíduos, pelo teste de Lilliefors (Campos, 1979). Posteriormente, foram submetidos à análise de variância com aplicação do teste $\mathrm{F}$ e dos valores médios, quando significativos, comparados entre si pelo teste de Tukey a $5 \%$. Não foi necessária nenhuma transformação de dados. Cada vinhedo foi considerado uma área, sendo os tratamentos considerados os locais de coleta ( $\mathrm{Lp}, \mathrm{El}, \mathrm{Lr})$, com três repetições por profundidade. Também foi realizada uma análise de componentes principais (ACP), por meio do programa XLSTAT (Addinsoft ${ }^{\circledR}, 2010$ ), para cada camada avaliada e entre os locais de coleta, cujas variáveis selecionadas foram as que apresentaram correlações de Pearson maiores que 0,6 entre si. A ACP é utilizada para reduzir as dimensões dos dados e, consequentemente, facilitar a análise por meio do gráfico do círculo de correlações (Herlihy \& McCarthy, 2006).

\section{RESULTADOS E DISCUSSÃO}

\section{Atributos físicos do vinhedo 1}

No vinhedo 1 , onde não há tráfego de máquinas, quando o solo foi influenciado, decorreu do pisoteio (humano) na região compreendida pelas posições El e Lr. Para MaP e PT, verificaram-se diferenças, na profundidade de 0,05-0,10 m, entre a Lp e a Lr, com maiores valores para $\mathrm{Lp}$, intermediários para a $\mathrm{El} \mathrm{e}$ menores para Lr (Quadro 2). Com maior valor de MaP na Lp, a PT também apresentou o mesmo padrão, pois a MaP é a primeira que sofre interferência no processo de compactação (Reichert et al., 2007). Isso também pode ter influenciado a Ug, que foi superior na Lp em relação à Lr. Aparentemente, a reduzida pressão causada pelo pisoteio foi suficiente para alterar a MaP. Em estudo conduzido em um Cambissolo Háplico em Bento Gonçalves, RS, também se observou redução da MaP na entrelinha em relação à linha de plantio de um vinhedo, mas essa diferenciação ocorreu em razão do tráfego de máquinas agrícolas (Rosa et al., 2009). Tanto a MeP como a MiP não foram influenciadas pelo manejo do vinhedo 1 (Quadro 2).

A Ds foi superior na El em relação à Lp na camada de 0,10-0,15 m, ambas não diferindo da Lr, podendo indicar o efeito do manejo para as podas, colheitas e pulverizações com aplicação de forças no solo mais próximas às plantas de videira. No entanto, esses valores encontrados são menores do que o limite para considerar o solo compactado (Reinert \& Reichert, 2006).

Adicionalmente, os valores de MaP são adequados e suficientes para permitir a drenagem do solo em todas as posições, sempre próximos dos $0,200 \mathrm{~m}^{3} \mathrm{~m}^{-3}$ (Xu et al., 1992; van Lier, 2001). Os atributos relacionados à agregação e estabilidade dos agregados (DMGsa, DMGea e IEA) também foram semelhantes, indicando que, em relação à estrutura do solo, o manejo não causou efeitos nos diferentes pontos de amostragem, submetidos ou não à ação antrópica por meio do pisoteio.

No vinhedo 1, não foram verificados efeitos das posições de amostragem sobre a $\mathrm{Rp}$, mas todos os valores determinados foram $\geq 2,5 \mathrm{MPa}$. Nas 
Quadro 2. Atributos físicos do solo em três posições, em relação à linha de plantio e em quatro profundidades dos três vinhedos avaliados, em Cambissolo Háplico

\begin{tabular}{|c|c|c|c|c|c|c|c|c|c|c|c|}
\hline Camada & Posição $^{(1)}$ & Ds & $\mathbf{R p}$ & Ug & $\mathrm{MaP}$ & $\mathrm{MeP}$ & MiP & PT & DMGsa & DMGea & IEA \\
\hline & & $\mathrm{kg} \mathrm{dm}^{-3}$ & $\mathrm{MPa}$ & & & $-\mathrm{m}^{3} \mathrm{~m}^{-3}$ & & & 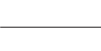 & - & \\
\hline & & & & & & Vinhedo 1 & & & & & \\
\hline \multirow[t]{4}{*}{$0,00-0,05 \mathrm{~m}$} & Lp & $1,21 \mathrm{a}$ & $2,5 \mathrm{a}$ & 0,425 a & $0,210 \mathrm{a}$ & $0,048 \mathrm{a}$ & $0,256 \mathrm{a}$ & $0,514 \mathrm{a}$ & $1,743 \mathrm{a}$ & $1,310 \mathrm{a}$ & $0,757 \mathrm{a}$ \\
\hline & $\mathrm{El}$ & $1,24 \mathrm{a}$ & $2,9 \mathrm{a}$ & $0,404 \mathrm{a}$ & $0,185 \mathrm{a}$ & $0,042 \mathrm{a}$ & $0,271 \mathrm{a}$ & $0,499 \mathrm{a}$ & $1,810 \mathrm{a}$ & $1,187 \mathrm{a}$ & $0,660 \mathrm{a}$ \\
\hline & $\mathrm{Lr}$ & $1,29 \mathrm{a}$ & $2,9 \mathrm{a}$ & $0,400 \mathrm{a}$ & $0,181 \mathrm{a}$ & $0,048 \mathrm{a}$ & $0,286 \mathrm{a}$ & $0,515 \mathrm{a}$ & $2,000 \mathrm{a}$ & $1,370 \mathrm{a}$ & $0,687 \mathrm{a}$ \\
\hline & CV (\%) & 3,2 & 17,3 & 9,5 & 12,5 & 23,2 & 11,5 & 6,9 & 9,8 & 7,7 & 8,7 \\
\hline \multirow[t]{4}{*}{$0,05-0,10 \mathrm{~m}$} & Lp & $1,28 \mathrm{a}$ & $2,9 \mathrm{a}$ & $0,391 \mathrm{a}$ & $0,214 \mathrm{a}$ & $0,052 \mathrm{a}$ & $0,233 \mathrm{a}$ & 0,499 a & $1,927 \mathrm{a}$ & $1,110 \mathrm{a}$ & $0,580 \mathrm{a}$ \\
\hline & $\mathrm{El}$ & $1,34 \mathrm{a}$ & $3,3 \mathrm{a}$ & $0,352 \mathrm{ab}$ & $0,185 \mathrm{ab}$ & 0,039 a & $0,246 \mathrm{a}$ & $0,470 \mathrm{ab}$ & $1,860 \mathrm{a}$ & $1,163 \mathrm{a}$ & $0,627 \mathrm{a}$ \\
\hline & $\mathrm{Lr}$ & $1,36 \mathrm{a}$ & $2,7 \mathrm{a}$ & $0,331 \mathrm{~b}$ & $0,171 \mathrm{~b}$ & $0,038 \mathrm{a}$ & $0,241 \mathrm{a}$ & $0,450 \mathrm{~b}$ & $2,083 \mathrm{a}$ & $1,207 \mathrm{a}$ & $0,583 \mathrm{a}$ \\
\hline & CV (\%) & 3,5 & 10,8 & 6,5 & 9,0 & 24,3 & 8,7 & 3,9 & 10,0 & 9,4 & 12,0 \\
\hline \multirow[t]{4}{*}{$0,10-0,15 \mathrm{~m}$} & Lp & $1,27 \mathrm{~b}$ & $3,1 \mathrm{a}$ & $0,396 \mathrm{a}$ & 0,217 a & 0,049 a & $0,237 \mathrm{a}$ & 0,503 a & $1,883 \mathrm{a}$ & $1,030 \mathrm{a}$ & $0,550 \mathrm{a}$ \\
\hline & $\mathrm{El}$ & $1,37 \mathrm{a}$ & $2,9 \mathrm{a}$ & $0,357 \mathrm{a}$ & $0,183 \mathrm{a}$ & 0,039 a & $0,269 \mathrm{a}$ & $0,490 \mathrm{a}$ & $2,057 \mathrm{a}$ & $1,017 \mathrm{a}$ & $0,497 \mathrm{a}$ \\
\hline & $\mathrm{Lr}$ & $1,33 \mathrm{ab}$ & $2,5 \mathrm{a}$ & $0,344 \mathrm{a}$ & $0,184 \mathrm{a}$ & $0,045 \mathrm{a}$ & $0,229 \mathrm{a}$ & $0,458 \mathrm{a}$ & $1,897 \mathrm{a}$ & $1,037 \mathrm{a}$ & $0,557 \mathrm{a}$ \\
\hline & CV (\%) & 2,5 & 15,4 & 7,0 & 11,5 & 21,5 & 8,8 & 6,0 & 10,5 & 8,8 & 16,0 \\
\hline \multirow[t]{5}{*}{$0,15-0,20 \mathrm{~m}$} & $\mathrm{Lp}$ & $1,30 \mathrm{a}$ & $2,8 \mathrm{a}$ & $0,381 \mathrm{a}$ & $0,199 \mathrm{a}$ & $0,042 \mathrm{a}$ & $0,251 \mathrm{a}$ & 0,493 a & $1,853 \mathrm{a}$ & $0,923 \mathrm{a}$ & $0,497 \mathrm{a}$ \\
\hline & El & $1,36 \mathrm{a}$ & $2,9 \mathrm{a}$ & $0,351 \mathrm{a}$ & $0,170 \mathrm{a}$ & $0,046 \mathrm{a}$ & $0,260 \mathrm{a}$ & $0,476 \mathrm{a}$ & $1,897 \mathrm{a}$ & $0,843 \mathrm{a}$ & $0,450 \mathrm{a}$ \\
\hline & $\mathrm{Lr}$ & $1,32 \mathrm{a}$ & $2,5 \mathrm{a}$ & $0,376 \mathrm{a}$ & $0,174 \mathrm{a}$ & $0,041 \mathrm{a}$ & $0,281 \mathrm{a}$ & 0,496 a & $2,070 \mathrm{a}$ & 0,933 a & $0,460 \mathrm{a}$ \\
\hline & CV (\%) & 4,6 & 21,1 & 5,2 & 12,1 & 25,2 & 12,6 & 3,83 & 13,2 & 11,9 & 15,4 \\
\hline & & & & & & Vinhedo 2 & & & & & \\
\hline \multirow[t]{4}{*}{$0,00-0,05 \mathrm{~m}$} & Lp & $1,00 \mathrm{a}$ & $1,7 \mathrm{c}$ & $0,670 \mathrm{a}$ & $0,161 \mathrm{a}$ & $0,085 \mathrm{a}$ & $0,412 \mathrm{a}$ & 0,658 a & $2,543 \mathrm{a}$ & $1,173 \mathrm{a}$ & $0,473 \mathrm{a}$ \\
\hline & El & $1,00 \mathrm{a}$ & $2,9 \mathrm{~b}$ & 0,623 a & $0,170 \mathrm{a}$ & $0,068 \mathrm{a}$ & $0,421 \mathrm{a}$ & $0,658 \mathrm{a}$ & $2,460 \mathrm{a}$ & $1,077 \mathrm{a}$ & $0,440 \mathrm{a}$ \\
\hline & Lr & $1,11 \mathrm{a}$ & $4,2 \mathrm{a}$ & 0,603 a & $0,117 \mathrm{a}$ & $0,060 \mathrm{a}$ & $0,532 \mathrm{a}$ & $0,708 \mathrm{a}$ & $2,393 \mathrm{a}$ & $1,147 \mathrm{a}$ & $0,487 \mathrm{a}$ \\
\hline & CV (\%) & 19,2 & 8,6 & 27,0 & 17,5 & 38,3 & 17,8 & 12,5 & 9,9 & 19,0 & 26,8 \\
\hline \multirow[t]{4}{*}{$0,05-0,10 \mathrm{~m}$} & Lp & $1,32 \mathrm{a}$ & $2,9 \mathrm{a}$ & $0,420 \mathrm{a}$ & $0,128 \mathrm{a}$ & $0,090 \mathrm{a}$ & $0,333 \mathrm{a}$ & $0,551 \mathrm{a}$ & $2,637 \mathrm{a}$ & 0,977 a & $0,373 \mathrm{a}$ \\
\hline & $\mathrm{El}$ & $1,31 \mathrm{a}$ & $3,0 \mathrm{a}$ & $0,397 \mathrm{a}$ & $0,151 \mathrm{a}$ & $0,052 \mathrm{a}$ & $0,318 \mathrm{a}$ & $0,521 \mathrm{a}$ & $2,493 \mathrm{a}$ & $1,057 \mathrm{a}$ & $0,423 \mathrm{a}$ \\
\hline & $\mathrm{Lr}$ & $1,39 \mathrm{a}$ & $2,7 \mathrm{a}$ & $0,373 \mathrm{a}$ & $0,127 \mathrm{a}$ & $0,040 \mathrm{a}$ & $0,350 \mathrm{a}$ & $0,516 \mathrm{a}$ & $2,597 \mathrm{a}$ & 0,993 a & $0,390 \mathrm{a}$ \\
\hline & CV (\%) & 5,0 & 13,4 & 5,9 & 20,3 & 49,2 & 5,85 & 3,7 & 8,6 & 17,0 & 21,8 \\
\hline \multirow[t]{4}{*}{$0,10-0,15 \mathrm{~m}$} & Lp & $1,31 \mathrm{~b}$ & $3,2 \mathrm{a}$ & 0,393 a & $0,119 \mathrm{a}$ & $0,073 \mathrm{a}$ & $0,321 \mathrm{a}$ & $0,514 \mathrm{a}$ & $2,603 \mathrm{a}$ & $0,877 \mathrm{a}$ & $0,337 \mathrm{a}$ \\
\hline & $\mathrm{El}$ & $1,40 \mathrm{a}$ & $3,6 \mathrm{a}$ & $0,360 \mathrm{a}$ & $0,124 \mathrm{a}$ & $0,043 \mathrm{a}$ & $0,337 \mathrm{a}$ & $0,504 \mathrm{a}$ & $2,727 \mathrm{a}$ & $1,010 \mathrm{a}$ & $0,377 \mathrm{a}$ \\
\hline & $\mathrm{Lr}$ & $1,37 \mathrm{ab}$ & $2,8 \mathrm{a}$ & $0,377 \mathrm{a}$ & $0,136 \mathrm{a}$ & $0,047 \mathrm{a}$ & $0,338 \mathrm{a}$ & $0,521 \mathrm{a}$ & $2,570 \mathrm{a}$ & 0,933 a & $0,363 \mathrm{a}$ \\
\hline & CV (\%) & 1,8 & 11,4 & 4,0 & 19,1 & 33,3 & 6,6 & 2,7 & 4,4 & 19,8 & 20,5 \\
\hline \multirow[t]{5}{*}{$0,15-0,20 \mathrm{~m}$} & Lp & $1,31 \mathrm{a}$ & $3,0 \mathrm{a}$ & $0,410 \mathrm{a}$ & 0,135 a & $0,055 \mathrm{a}$ & $0,341 \mathrm{a}$ & $0,531 \mathrm{a}$ & $2,590 \mathrm{a}$ & $0,800 \mathrm{a}$ & $0,310 \mathrm{a}$ \\
\hline & $\mathrm{El}$ & $1,35 \mathrm{a}$ & $3,0 \mathrm{a}$ & $0,393 \mathrm{a}$ & $0,125 \mathrm{a}$ & $0,041 \mathrm{~b}$ & $0,362 \mathrm{a}$ & 0,529 a & $2,407 \mathrm{a}$ & 0,763 a & $0,320 \mathrm{a}$ \\
\hline & $\mathrm{Lr}$ & $1,42 \mathrm{a}$ & $2,5 \mathrm{a}$ & $0,360 \mathrm{a}$ & $0,120 \mathrm{a}$ & $0,037 \mathrm{~b}$ & $0,345 \mathrm{a}$ & 0,503 a & $2,557 \mathrm{a}$ & $0,700 \mathrm{a}$ & $0,277 \mathrm{a}$ \\
\hline & CV (\%) & 6,8 & 7,8 & 14,0 & 35,5 & 11,1 & 11,68 & 7,0 & 5,9 & 27,9 & 33,0 \\
\hline & & & & & & Vinhedo 3 & & & & & \\
\hline \multirow[t]{4}{*}{$0,00-0,05 \mathrm{~m}$} & Lp & $0,96 \mathrm{~b}$ & $2,0 \mathrm{~b}$ & 0,675 a & $0,203 \mathrm{a}$ & $0,082 \mathrm{a}$ & $0,352 \mathrm{a}$ & 0,637 a & $2,017 \mathrm{a}$ & $1,550 \mathrm{a}$ & $0,773 \mathrm{a}$ \\
\hline & $\mathrm{El}$ & $0,70 \mathrm{c}$ & $1,5 \mathrm{~b}$ & 0,615 a & $0,175 \mathrm{a}$ & $0,112 \mathrm{a}$ & $0,389 \mathrm{a}$ & 0,676 a & $2,150 \mathrm{a}$ & $1,510 \mathrm{a}$ & $0,710 \mathrm{a}$ \\
\hline & $\mathrm{Lr}$ & $1,24 \mathrm{a}$ & $4,3 \mathrm{a}$ & $0,378 \mathrm{a}$ & $0,116 \mathrm{a}$ & $0,064 \mathrm{a}$ & $0,285 \mathrm{a}$ & 0,465 a & $2,387 \mathrm{a}$ & $1,317 \mathrm{a}$ & $0,553 \mathrm{a}$ \\
\hline & CV (\%) & 8,9 & 20,7 & 39,5 & 28,6 & 47,7 & 36,6 & 23,0 & 7,3 & 19,5 & 23,3 \\
\hline \multirow[t]{4}{*}{$0,05-0,10 \mathrm{~m}$} & Lp & $1,25 \mathrm{~b}$ & $3,0 \mathrm{~b}$ & $0,422 \mathrm{a}$ & $0,175 \mathrm{a}$ & $0,064 \mathrm{a}$ & $0,280 \mathrm{a}$ & $0,519 \mathrm{a}$ & $2,330 \mathrm{a}$ & $1,533 \mathrm{a}$ & $0,657 \mathrm{a}$ \\
\hline & El & $1,34 \mathrm{ab}$ & $3,5 \mathrm{~b}$ & $0,382 \mathrm{a}$ & $0,138 \mathrm{a}$ & $0,059 \mathrm{a}$ & $0,315 \mathrm{a}$ & $0,511 \mathrm{a}$ & $2,280 \mathrm{a}$ & $1,117 \mathrm{a}$ & $0,497 \mathrm{a}$ \\
\hline & $\mathrm{Lr}$ & $1,49 \mathrm{a}$ & $4,5 \mathrm{a}$ & $0,308 \mathrm{a}$ & $0,109 \mathrm{a}$ & $0,046 \mathrm{a}$ & $0,302 \mathrm{a}$ & $0,456 \mathrm{a}$ & $2,407 \mathrm{a}$ & $0,887 \mathrm{a}$ & $0,370 \mathrm{a}$ \\
\hline & CV (\%) & 7,0 & 8,6 & 18,3 & 25,3 & 15,9 & 7,4 & 9,5 & 9,3 & 24,2 & 25,6 \\
\hline \multirow[t]{4}{*}{$0,10-0,15 \mathrm{~m}$} & $\mathrm{Lp}$ & $1,33 \mathrm{a}$ & $3,9 \mathrm{a}$ & $0,367 \mathrm{a}$ & $0,138 \mathrm{a}$ & $0,057 \mathrm{a}$ & $0,285 \mathrm{a}$ & $0,480 \mathrm{a}$ & $2,310 \mathrm{a}$ & $1,033 \mathrm{a}$ & $0,450 \mathrm{a}$ \\
\hline & $\mathrm{El}$ & $1,34 \mathrm{a}$ & $3,5 \mathrm{a}$ & $0,385 \mathrm{a}$ & $0,129 \mathrm{a}$ & $0,047 \mathrm{a}$ & $0,333 \mathrm{a}$ & 0,509 a & $2,587 \mathrm{a}$ & $1,053 \mathrm{a}$ & $0,410 \mathrm{a}$ \\
\hline & $\mathrm{Lr}$ & $1,40 \mathrm{a}$ & $4,2 \mathrm{a}$ & $0,346 \mathrm{a}$ & $0,120 \mathrm{a}$ & $0,068 \mathrm{a}$ & $0,295 \mathrm{a}$ & 0,483 a & $2,450 \mathrm{a}$ & $0,720 \mathrm{a}$ & $0,293 \mathrm{a}$ \\
\hline & CV (\%) & 8,9 & 17,0 & 21,6 & 31,2 & 45,1 & 8,0 & 12,1 & 6,8 & 34,2 & 36,6 \\
\hline \multirow[t]{4}{*}{$0,15-0,20 \mathrm{~m}$} & Lp & $1,33 \mathrm{a}$ & $3,3 \mathrm{a}$ & $0,354 \mathrm{a}$ & $0,148 \mathrm{a}$ & $0,047 \mathrm{a}$ & $0,276 \mathrm{a}$ & $0,471 \mathrm{a}$ & $2,393 \mathrm{a}$ & $1,113 \mathrm{a}$ & $0,460 \mathrm{a}$ \\
\hline & $\mathrm{El}$ & $1,41 \mathrm{a}$ & $3,6 \mathrm{a}$ & $0,348 \mathrm{a}$ & $0,132 \mathrm{a}$ & $0,041 \mathrm{a}$ & $0,316 \mathrm{a}$ & 0,489 a & $2,470 \mathrm{a}$ & $0,893 \mathrm{a}$ & $0,363 \mathrm{a}$ \\
\hline & $\mathrm{Lr}$ & $1,40 \mathrm{a}$ & $3,3 \mathrm{a}$ & $0,326 \mathrm{a}$ & $0,126 \mathrm{a}$ & $0,030 \mathrm{a}$ & $0,300 \mathrm{a}$ & 0,455 a & $2,657 \mathrm{a}$ & $0,903 \mathrm{a}$ & $0,340 \mathrm{a}$ \\
\hline & CV (\%) & 5,4 & 14,5 & 6,7 & 14,5 & 50,0 & 9,2 & 4,2 & 9,4 & 35,4 & 33,1 \\
\hline
\end{tabular}

(1) Lp: Linha de plantio; El: Entre a linha de plantio e a linha do rodado; e Lr: Linha do rodado. Médias de uma mesma camada de solo seguidas pela mesma letra na coluna não diferem entre si (Tukey, $p<0,05)$. 
profundidades de 0,05-0,10 e 0,10-0,15 m, verificaramse valores superiores a 3,0 MPa para a El e Lp, respectivamente (Quadro 2), indicando existência de condições restritivas ao desenvolvimento radicular para diversas culturas, inclusive para a videira (Taylor et al., 1966; Echenique et al., 2007). O histórico de uso do solo, anteriormente à implantação do vinhedo, associado ao intenso revolvimento do solo, refletiu diretamente no atributo físico $\mathrm{Rp}$.

Dessa forma, em razão da ausência de tráfego de máquinas e por ser um vinhedo novo, para a maioria dos atributos físicos avaliados, não foram detectadas diferenças entre posições de amostragem, indicando pequeno efeito do pisoteio humano sobre os atributos físicos do solo.

\section{Atributos físicos do vinhedo 2}

No vinhedo 2 , que sofre tráfego de máquinas agrícolas, observaram-se diferenças entre as posições de coleta para a Rp na camada de 0,00-0,05 m (mesmo sem diferenças para Ug), onde verificou-se o maior valor na $\operatorname{Lr}(4,2 \mathrm{MPa})$, seguido da $\mathrm{El}(2,9 \mathrm{MPa})$ e com o menor valor na $\mathrm{Lp}(1,7 \mathrm{MPa})$ (Quadro 2). Esse atributo evidenciou uma variação do estado físico do solo causado pela pressão dos rodados no local de tráfego, onde a $\mathrm{Rp}$ atingiu valor considerado restritivo ao crescimento radicular (Echenique et al., 2007). Além disso, na Lr, observou-se aumento de $11 \%$ para a Ds e redução de 38 \% para a MaP, em comparação à Lp (Quadro 2). Na posição El, a Rp apresentou valor limitante, mas não restritivo, e na Lp não verificouse resistência considerada crítica ao desenvolvimento radicular para nenhuma cultura (Taylor et al., 1966; Nesmith, 1987).

Na camada de 0,10-0,15 m, a Ds apresentou diferença entre a Lp e a El, com valores intermediários na Lr. O esperado seria essa diferença ocorrer entre Lp e Lr, mas o maior valor foi verificado na $\mathrm{El}$, que pode em certas ocasiões também ter sofrido tráfego, bem como influência desse, em razão da proximidade com a Lr, que se apresenta mais compactada em relação à Lp.

Para a MeP, somente verificaram-se maiores valores na Lp em relação às outras posições na camada de $0,15-0,20 \mathrm{~m}$. Para as demais camadas, não houve diferenças significativas (Quadro 2). Isso pode ser por causa da maior destruição da $\mathrm{MeP}$ ocasionada pela pressão das máquinas na Lr e El, transformando-a em poros menores, o que é corroborado pela correlação alta e negativa entre a $\mathrm{MeP}$ dessa camada com a $\mathrm{Rp}$ da de 0,00-0,05 m $(r=-0,75, \mathrm{p}<0,05)$ e a Ds da de 0,10-0,15 m $(r=-0,73, p<0,05)$. Também foram verificadas correlações negativas entre a $\mathrm{MeP}$ com a Ds para a camada de $0,00-0,05 \mathrm{~m}(\mathrm{r}=-0,91, \mathrm{p}<0,05)$, entre a MeP da de 0,10-0,15 m e a Rp da de 0,0-0,05 $(r=-0,69, p<0,05)$; e correlações positivas entre a Ds da camada de $0,10-0,15 \mathrm{~m}$ e a $\mathrm{Rp}$ das camadas de $0,00-0,05 \mathrm{~m}(\mathrm{r}=0,75, \mathrm{p}<0,05)$ e $0,10-0,15 \mathrm{~m}(\mathrm{r}=0,67$, $\mathrm{p}<0,05)$. Esse padrão demonstra o efeito negativo do tráfego de máquinas, acarretando em aumento dos valores de $\mathrm{Ds}$ e $\mathrm{Rp}$, com consequências negativas para a $\mathrm{MeP}$.

A MaP no vinhedo 2 apresentou valores inferiores (proporcionalmente) àqueles encontrados no vinhedo 1 , o que pode estar atrelado à diferença granulométrica entre os dois (Quadro 1), sendo verificado, na camada de 0,00-0,20 m, valores de correlação de $r=0,60 ; r=-0,45$; e $r=-0,52$, respectivamente, para areia, silte e argila $(\mathrm{p}<0,05)$ e a MaP. A redução da MaP também é por causa da compactação do solo causada pelo tráfego no vinhedo 2, o que é corroborado pelos valores de correlações (altos e negativos) entre a MaP (camada de 0,00-0,05 m) e a Ds das camadas de 0,10-0,15 m $(\mathrm{r}=-0,86, \mathrm{p}<0,05)$ e $0,15-0,20 \mathrm{~m}(\mathrm{r}=-0,72, \mathrm{p}<0,05)$, e a Rp da camada de 0,05-0,10 m ( $r=-0,72, \mathrm{p}<0,05)$. Para a camada de 0,00-0,05 m, é possível aferir redução de cerca de $30 \%$ na $\mathrm{MaP}$ da $\mathrm{Lr}$, em relação à $\mathrm{Lp}$ (Quadro 2), ao mesmo tempo em que essa chega em valor próximo àquele tido como base de volume de poros que se apresentem livres de água para permitir o fluxo de gases no solo (van Lier, 2001; Klein et al., 2008).

A baixa permeabilidade à água e ao ar em solos com predominância da MiP, como no caso do vinhedo 2 , que apresenta em todos locais e profundidades mais de $60 \%$ da PT composta pela MiP e chegando a $75 \%$ na camada 0,00-0,05 m na Lr, determina elevada capacidade de retenção de água e prejudica o sistema radicular, em razão da escassez de oxigênio às raízes (Dalbó et al., 2011). E, ainda, quando presente em regiões com elevada temperatura e com elevados índices de pluviosidade, aumenta a propensão à ocorrência de doenças fúngicas, o que pode prejudicar ainda mais a produtividade da cultura (Protas, 2003).

Em relação ao atributo DMGsa, é possível verificar valores proporcionalmente maiores, se comparado com os encontrados no vinhedo 1 . No entanto, esses maiores agregados secos ao ar, que apresentaram $r=0,63$ $(p<0,05)$ com os teores de argila (camada de 0,00-0,20 $\mathrm{m})$, não se mantiveram estáveis em água, sendo verificado correlação negativa $(r=-0,39, p<0,05)$ entre DMGea e os teores de argila. Isso pode estar relacionado ao efeito do tráfego sobre a estrutura do solo, onde os agregados naturais são destruídos e ocorre aumento daqueles formados por efeito de compactação, os quais são menos estáveis, fato evidenciado pelo menor IEA $(\mathrm{r}=-0,60, \mathrm{p}<0,05$, com os teores de argila na camada de $0,00-0,20 \mathrm{~m}$ ), que não chegou a atingir 0,50 no vinhedo 2 (Quadro 2) (Carpenedo \& Mielniczuk, 1990; Albuquerque et al., 2005; Salton et al., 2008), mesmo com maior teor de argila e, portanto, mais agente cimentante que o vinhedo 1 .

Portanto, no vinhedo 2, tem-se a formação de agregados maiores em razão da destruição de agregados naturais pela compactação causada pelo tráfego, que forma agregados de maior tamanho (Bronick \& Lal, 2005). Esse comportamento pode ser explicado pela aproximação das partículas causada pela pressão das máquinas agrícolas, resultando em agregados maiores (maiores índices de DMGsa), porém 
sem o processo de estabilização desses, já que apenas a entrada de água é suficiente para desestabilizá-los (DMGea consideravelmente menor no vinhedo 2, proporcionalmente aos valores verificados para o vinhedo 1). Isso porque não se formaram pela ação dos agentes cimentantes permanentes e temporários, que estão ligados aos processos biológicos de formação e estabilização desses agregados (Tisdall \& Oades, 1982; Carpenedo \& Mielniczuk, 1990; Salton et al., 2008).

A correlação alta e negativa entre Ds com DMGea, sendo $r=-0,69(p<0,05)$ e $r=-0,76(p<0,05)$, respectivamente, para as camadas de 0,05-0,10 e 0,10-0,15 m, corrobora o efeito negativo do tráfego de máquinas, acarretando aumento dos valores de Ds e diminuição dos de DMGea. Também foram observados valores de correlação negativos entre IEA com a $\operatorname{Ds}(r=-0,60, p<0,05)$ e a $\operatorname{Rp}(r=-0,36, p<0,05)$, ambos para a camada de 0,00-0,20 m.

\section{Atributos físicos do vinhedo 3}

Para o vinhedo 3, verificou-se efeito significativo das posições de amostragem sobre os atributos Ds e $\mathrm{Rp}$ nas camadas até $0,10 \mathrm{~m}$, com valores variando entre 0,70 e $1,49 \mathrm{~kg} \mathrm{dm}^{-3}$ para a Ds e entre 1,51 e 4,50 MPa para a Rp (Quadro 2). Os maiores valores de Ds foram encontrados na posição de coleta Lr, mesmo local onde também foram observados os maiores valores para $\mathrm{Rp}$, demonstrando alta correlação entre esses dois atributos $(r=0,75, r=0,67, p<0,05$, para as camadas superficiais do solo), consequência da maior intensidade do tráfego e compressão do solo pelas máquinas associada ao maior tempo de implantação desse vinhedo. Também verificou-se correlação negativa da PT com a Ds na camada superficial do solo $(r=-0,79$, $\mathrm{p}<0,05)$ e não foram verificadas diferenças estatísticas entre as posições de coleta para PT. Mesmo sem apresentar diferenças na PT $(0,00-0,05 \mathrm{~m})$, observou-se redução de $30 \%$ na Lr em relação à Lp, o que corrobora com os maiores valores de Ds e Rp na Lr.

Na camada superficial, a Ds foi maior na Lr e menor na El, enquanto na camada de 0,05-0,10 m a El não diferiu das demais, onde essa posição é intermediária à Lp (que sofreu menor alteração dos atributos físicos) e à Lr (mais alterada). Esse é o padrão observado nos vinhedos que sofrem tráfego de máquinas agrícolas. A Rp, que possui alta e positiva correlação com a Ds, como mencionado anteriormente, evidenciou a variação ocorrida no solo na posição Lr, apresentando valor superior a $100 \%$ em relação às posições El e Lp, que não diferiram entre si. Ao estudar um Cambissolo Húmico com $443 \mathrm{~g} \mathrm{~kg}^{-1}$ de argila sob diferentes usos em Lages, SC, com e sem preparo do solo, Andrade et al. (2010) observaram valores de Ds entre 1,13 e $1,38 \mathrm{~kg} \mathrm{dm}^{-3}$, com os maiores valores a uma profundidade próxima dos 0,15 m. A Rp nesse solo acompanhou o aumento da Ds, com valores entre 0,13 e $1,54 \mathrm{MPa}$, confirmando a boa relação entre esses atributos para inferir sobre as condições para o crescimento radicular. Também em um estudo em um Cambissolo Háplico em Bento Gonçalves, RS, observou-se na entrelinha em relação à linha de plantio de um vinhedo, alteração em atributos físicos, como aumento da Ds na entrelinha, decorrente do tráfego de máquinas agrícolas (Rosa et al., 2009).

De acordo com o valor de Ds crítica proposta por Reichert et al. (2003) de $1,55 \mathrm{~kg} \mathrm{dm}^{-3}$ para solos com textura média (20 a $55 \%$ de argila), os valores verificados na $\operatorname{Lr}$ do vinhedo 3 , bem como na $\operatorname{Lr}$ do vinhedo 2 , ambos para a camada de 0,05-0,10 m, causam problemas para o crescimento radicular, o que também foi verificado por Suzuki (2005), em um Argissolo Vermelho distrófico latossólico (278 g kg-1 de argila, $331 \mathrm{~g} \mathrm{~kg}^{-1}$ de silte e $391 \mathrm{~g} \mathrm{~kg}^{-1}$ de areia), em Alto das Canas, RS, causando redução no crescimento radicular da soja.

Juntamente a esses valores de Ds, é importante salientar que os valores de Rp, observados nos solos do vinhedo 2 e 3 (Quadro 2), foram superiores a 3,0 $\mathrm{MPa}$ na posição Lr, sendo considerados limitantes ou mesmo restritivos ao crescimento radicular da videira e das plantas de cobertura (Taylor et al., 1966; Nesmith, 1987; Merotto Jr. \& Mundstock, 1999; Echenique et al., 2007). Essa limitação ainda pode ser maior ou menor dependendo da umidade do solo, como exposto por Genro Junior et al. (2004), os quais verificaram diferentes valores de $R p$ ao realizarem amostragens em um Latossolo em Ijuí, $\mathrm{RS}$, que variaram inversamente com a umidade volumétrica do solo. Neste trabalho, foram encontradas correlações negativas entre a $\mathrm{Rp}$ da camada de 0,00-0,05 $\mathrm{m}$ e a Ug da de 0,05-0,10 m $(r=-0,69, p<0,05)$ e entre a $R p$ da de $0,05-0,10 \mathrm{~m}$ e a Ug da de 0,15-0,20 m ( $\mathrm{r}=-0,69, \mathrm{p}<0,05)$.

$\mathrm{O}$ vinhedo 3 , na camada de 0,05-0,10 m, mesmo na posição $\mathrm{Lp}$, apresentou elevados valores de Rp, o que pode interferir negativamente no crescimento radicular e, consequentemente, na produção das videiras (Echerique et al., 2007). Nesse vinhedo, apesar de o solo ter sofrido maior intensidade de tráfego e maior compressão do solo, foram observados valores de DMGsa, DMGea e IEA intermediários, em relação aos vinhedos 1 e 2 , o que pode estar relacionado ao maior teor de matéria orgânica do solo (MOS) nessa área ( $\mathrm{r}=0,78, \mathrm{p}<0,05$, com DMGea), comparativamente ao solo dos demais vinhedos (Quadro 1), o que pode aumentar o tamanho dos agregados estáveis em água. Esses maiores teores de MOS são decorrentes do uso de espécies de plantas de cobertura do solo (aveia e ervilhaca), que, em razão do maior tempo de implantação do vinhedo 3 , pode ter favorecido o aumento dos teores de MOS. Os maiores teores de MOS contribuem na agregação, na consistência e na retenção de umidade dos solos, além de aumentar o número de ligações entre as partículas, proporcionando melhores condições à formação e estabilidade de macroagregados (Tisdall \& Oades, 
1982; Salton et al., 2008; Santos, 2008; Braida et al., 2011). Os maiores teores de MOS associados ao sistema radicular das espécies de plantas de cobertura do solo podem ter auxiliado na redução da ação negativa do tráfego sobre os agregados, em relação ao vinhedo 2 , fato evidenciado pelo IEA, que apresentou valores mais similares ao vinhedo 1 .

\section{Análise dos componentes principais (ACP)}

A distribuição das variáveis analisadas na ACP é apresentada na figura 1 , com variância acumulada de 67,99 \% (eixos F1 e F2), sendo, desse total, maior efeito expresso pelo eixo F1 (43,37\%). Verificou-se que o vinhedo 1 separou-se dos demais, formando um agrupamento das posições de coleta, principalmente por causa dos atributos MaP, IEA e DMGea, que ficaram todos em um mesmo quadrante, sendo a maior ênfase desses atributos dada à posição de Lp, em

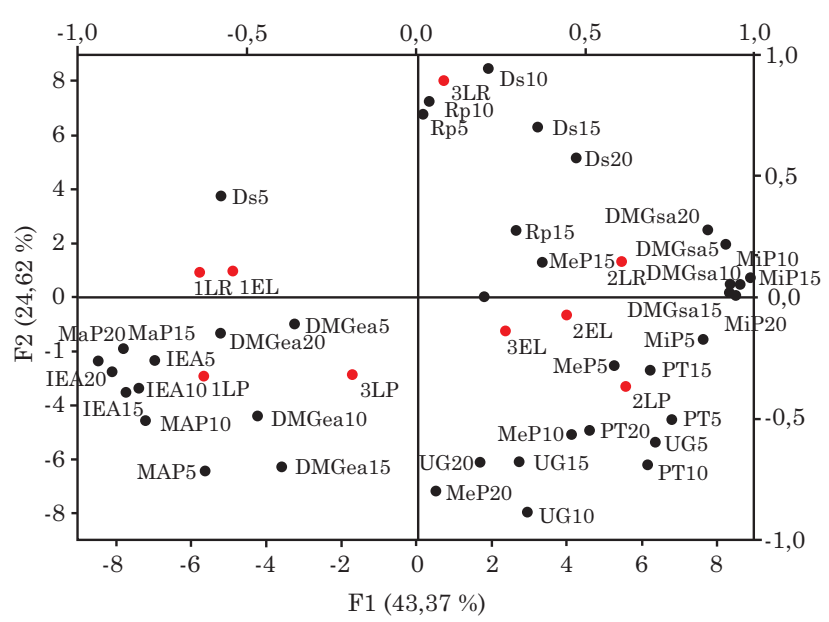

Figura 1. Diagrama de ordenaçãoproduzido por análise de componentes principais dos dados coletados. 1LP, 1EL, 1LR: vinhedo 1 nas posições linha de plantio, entre a linha do rodado e a linha de plantio e linha do rodado, respectivamente. $2 \mathrm{LP}, 2 \mathrm{EL}, 2 \mathrm{LR}$ : vinhedo 2 nas posições linha de plantio, entre a linha do rodado e a linha de plantio e linha do rodado, respectivamente. $3 \mathrm{LP}, 3 \mathrm{EL}$, 3LR: vinhedo 3 nas posições linha de plantio, entre a linha do rodado e a linha de plantio e linha do rodado, respectivamente. Atributos físicos do solo nas camadas 0,00-0,05 $\mathrm{m}, 0,05-0,10 \mathrm{~m}, 0,10-0,15 \mathrm{~m} \mathrm{e}$ 0,15-0,20 m, respectivamente: Ds (densidade do solo) $5,10,15$ e $20 ; R p$ (resistência à penetração) 5, 10, 15 e 20; PT (porosidade total) 5, 10, 15 e 20; MaP (macroporosidade) 5, 10, 15 e 20; MeP (mesoporosidade) 5, 10, 15 e 20; MiP (microporosidade ) $5,10,15$ e 20; DMGsa (diâmetro médio geométrico de agregados secos ao ar ) 5, 10, 15 e 20; DMGea (diâmetro médio geométrico de agregados estáveis em água) 5, 10, 15 e 20; IEA (indice de estabilidade dos agregados ) 5, 10, 15 e 20; e UG (umidade gravimétrica) $5,10,15$ e 20. comparação às posições Lr e El, que apresentaram maior proximidade do atributo Ds (0,00-0,05 m). Esse padrão indicou que nas posições de Lr e El, por serem aquelas que sofrem maior pisoteio humano para os tratos culturais do vinhedo, apresentaram maiores valores de Ds, corroborando com os dados apresentados no quadro 2. Para os atributos relacionadas à posição Lp (MaP, IEA e DMGea), verificou-se que esses remetem às boas e desejadas características físicas do solo, por evidenciarem condições favoráveis à drenagem e representarem a melhor agregação do solo do vinhedo 1 , em relação aos vinhedos 2 e 3.

Na posição Lp do vinhedo 1, a maior influência foi atribuída aos atributos IEA e MaP, portanto demonstrando nesse local, e mesmo no vinhedo, características de um solo com boa qualidade física e, por meio dessa, diferenciando o manejo realizado nesse vinhedo em relação aos demais vinhedos.

Próximo ao grupamento das posições do vinhedo 1, tem-se a posição Lp do vinhedo 3 . Essa aproximação é decorrente do atributo DMGea ao longo das camadas analisadas, o que pode estar relacionado ao maior teor de MOS, comparativamente ao solo dos demais vinhedos (Quadro 1), mantendo o tamanho dos agregados estáveis em água, com valores similares entre o vinhedo 1 e o 3, conforme verificado no quadro 2. No entanto, no vinhedo 3 a posição Lr se destacou das demais posições do próprio vinhedo, assim como dos vinhedos 1 e 2 , em razão dos atributos $\mathrm{Rp}$ (camadas de 0,00-0,10 m) e Ds (camadas de 0,10-0,20 m). Esse vinhedo é o que tem a maior intensidade de tráfego e há mais tempo sujeito a ele, com maiores valores de Ds e Rp, considerados críticos ao desenvolvimento da videira (Echenique et al., 2007).

A mesma posição (Lr) no vinhedo 2 também se aproximou de atributos que remetem à degradação física do solo, principalmente a $R p(0,15-0,20 \mathrm{~m})$, a MeP (0,10-0,15 m), a MiP (0,10-0,20 m) e o DMGsa (0,00-0,20 m), e se distanciou de atributos como o DMGea e o IEA, o que indicou que os agregados maiores (maior DMGsa) foram formados pela compactação causada pelo tráfego às custas da destruição dos agregados formados por processos naturais (Bronick \& Lal, 2005). Porém, esses agregados maiores do vinhedo 2 não são resistentes às forças de desagregação pelo rápido umedecimento e peneiramento em água, fato evidenciado pela maior distância do valor de DMGea e do IEA da posição Lr, e, consequentemente, maior aproximação da posição Lp do vinhedo 1. Esse padrão corroborou com os índices DMGea e IEA dos vinhedos 1 e 2 (Quadro 2). O tráfego também confere uma elevação do valor da $\mathrm{MiP}$ e redução do valor da $\mathrm{MaP}$ em razão da pressão exercida pelos rodados na superfície, pois essa é a primeira classe de poros influenciada no processo de compactação (Reichert et al., 2007).

As posições Lr e El do vinhedo 2 e El do vinhedo 3 também ficaram mais próximas do atributo $R p(0,10$ 0,15 e $0,15-0,20 \mathrm{~m}$ ) do que a $\operatorname{Lr}$ do vinhedo 3 , bem como estão mais próximas dos atributos PT, MeP, 
MiP e DMGsa, que por sua vez, excluindo a MeP, inferem em uma qualidade física mais depreciada nesses dois vinhedos, em comparação ao vinhedo 1.

A posição Lp do vinhedo 2 se diferenciou das demais, principalmente em relação à $\mathrm{PT}, \mathrm{MeP}$ e Ug. No entanto, bem como o caso da posição Lp do vinhedo 3, isso está mais condicionado a uma característica inerente ao solo do vinhedo do que causada pelo manejo, pois o solo desse vinhedo apresentou valor mais elevado de silte e argila (Quadro 1), portanto causando diferenciação granulométrica em relação aos vinhedos 1 e 3 .

As máquinas utilizadas nos vinhedos 2 e 3 aparentam não ter causado expressivas diferenças entre si quanto à deterioração do solo, mas há possibilidade de maior restrição no vinhedo 3 , por causa do maior tempo de uso e da maior intensidade de tráfego e carga aplicada, como também observado por Elaoud \& Chehaibi (2011), que mensuraram maior compactação do solo em razão da maior intensidade de tráfego. Nos vinhedos 2 e 3, principalmente em relação à posição Lr, e mesmo na El, verificou-se que intensivo uso de máquinas agrícolas causou degradação física do solo.

Dentre as posições de coletas e os vinhedos estudados, evidenciou-se, por meio da ACP, a separação da posição $\mathrm{Lr}$ do vinhedo 3 decorrente dos atributos Ds e Rp. Isso se deve ao maior tempo de uso, maior intensidade de tráfego e compressão aplicada ao solo, como também observado por Elaoud \& Chehaibi (2011), que mensuraram maior compactação do solo em razão da maior intensidade de tráfego. Assim, pode-se inferir que o manejo adotado no vinhedo 3 na posição Lr está ocasionando maior degradação da qualidade física do solo, quando comparado aos demais vinhedos.

\section{CONCLUSÕES}

1. O maior estado de compactação do solo ocorreu no sentido da linha de plantio para a do rodado, com maiores alterações nos atributos relacionados à porosidade do solo nos dois vinhedos submetidos ao tráfego de máquinas, à agregação e estabilidade de agregados no vinhedo 2 e à densidade do solo e da resistência à penetração no vinhedo 3 .

2 . No vinhedo 1 , por meio da ACP, evidenciaramse as melhores condições físicas do solo; entretanto, nos vinhedos 2 e 3 , encontrou-se a degradação física. A posição na linha do rodado do vinhedo 3 diferenciouse das demais posições e dos vinhedos, caracterizando maior degradação da qualidade física do solo.

\section{AGRADECIMENTOS}

À UFSC e EPAGRI, pela disponibilização de infraestrutura, materiais e apoio na pesquisa. Ao
MDA/SAF/CNPq, edital $\mathrm{N}^{0} 58 / 2010$, pelo auxílio financeiro. À CAPES, pela bolsa de mestrado concedida ao primeiro autor.

\section{LITERATURA CITADA}

ADDINSOFT. XLSTAT statistical analysis software. Version 2013.2. Disponível em: <www.xlstat.com>. Acesso em: 10 de Jul. 2010.

ALBUQUERQUE, J.A.; ARGENTON, J.; BAYER, C.; WILDNER, L.P. \& KUNTZE, M.A.G. Relação de atributos do solo com a agregação de um Latossolo Vermelho sob sistemas de preparo e plantas de verão para cobertura do solo. R. Bras. Ci. Solo, 29:415-424, 2005.

ANDRADE, A.P.; MAFRA, A.L.; BALDO, G.R.; PICCOLLA, C.D.; BERTOL, I. \& ALBUQUERQUE, J.A. Physical properties of a Humic Cambisol under tillage and cropping systems after 12 years. R. Bras. Ci. Solo, 34:219-226, 2010.

BEUTLER, A.N.; CENTURION, J.F.; CENTURION, M.A.P.C. \& SILVA, A.P. Efeito da compactação na produtividade de cultivares de soja em Latossolo Vermelho. R. Bras. Ci. Solo, 30:787-794, 2006.

BEUTLER, A.N. \& CENTURION, J.F. Soil compaction and fertilization in soybean productivity. Sci. Agríc., 61:626631, 2004.

BRAIDA, J.A.; BAYER, C.; ALBUQUERQUE, A. \& REICHERT, J.M. Matéria orgânica e seu efeito na física do solo. In: KLAUBERG FILHO, O., ed. Tópicos em ciência do solo. Viçosa, MG, Sociedade Brasileira de Ciência do Solo, 2011. v.7. p.221-278.

BRONICK, C.J. \& LAL, R. Soil structure and management: A review. Geoderma, 124:3-22, 2005.

CAMPOS, H. Estatística experimental não paramétrica. 3.ed. Piracicaba, Escola Superior de Agricultura Luiz de Queiroz, 1979. 373p.

CARPENEDO, V. \& MIELNICZUK, J. Estado de agregação e qualidade de agregados de Latossolos Roxos, submetidos a diferentes sistemas de manejo. R. Bras. Ci. Solo, 14:99$105,1990$.

COSTA, M.A.T.; TORMENA, C.A.; LUGÃO, S.M.B.; FIDALSKI, J.; NASCIMENTO, W.G. \& MEDEIROS, F.M. Resistência do solo à penetração e produção de raízes e de forragem em diferentes níveis de intensificação do pastejo. R. Bras. Ci. Solo, 36:993-1004, 2012 .

DALBÓ, M.A.; VEIGA, M. \& GARDIN, J.P.P. Desenvolvimento do sistema radicular da videira em função de porta-enxertos e de atributos físicos e químicos do solo. Agropec. Catarinense, 24:59-63, 2011.

DE MARIA, I.C.; CASTRO, O.M. \& DIAS, H.S. Atributos físicos do solo e crescimento radicular de soja em Latossolo Roxo sob diferentes métodos de preparo do solo. R. Bras. Ci. Solo, 23:703-709, 1999. 
ECHENIQUE, M.C.; APCARIAN, A.; REEB, P. \& ARUANI, M.C. Growth-yield relationship of grapevine cultivars on soils with hardened layers, Alto Valle of the Río Negro, southern wine-growing region of Argentina. Agric. Técn., 67:262-270, 2007.

ELAOUD, A. \& CHEHAIBI, S. Soil compaction due to tractor traffic. J. Failure Anal. Prev., 11:539-545, 2011.

EMPRESA BRASILEIRA DE PESQUISA AGROPECUÁRIA EMBRAPA. Centro Nacional de Pesquisa do Solo. Levantamento de reconhecimento dos solos do Estado de Santa Catarina. Rio de Janeiro, 1998. CD-ROM. (Boletim de Pesquisa, 6)

EMPRESA BRASILEIRA DE PESQUISA AGROPECUÁRIA EMBRAPA. Centro Nacional de Pesquisa do Solo. Sistema brasileiro de classificação de solos. 2.ed. Brasília, 2006. $306 \mathrm{p}$.

FERRERO, A.; USOWICZ, B. \& LIPIEC, J. Effects of tractor traffic on spatial variability of soil strength and water content in grass covered and cultivated sloping vineyard. Soil Till. Res., 84:127-138, 2005.

FIDALSKI, J.; TORMENA, C.A. \& SILVA, A.P. Least limiting water range and physical quality of soil under groundcover management systems in citrus. Sci. Agríc., 67:448-453, 2010.

FUENTES LLANILLO, R.; RICHART, A.; TAVARES FILHO, J.; GUIMARÃES, M. F. \& FERREIRA, R.R.M. Evolução de propriedades físicas do solo em função dos sistemas de manejo em culturas anuais. Semina: Ci. Agron., 27:205$220,2006$.

GENRO JUNIOR, S.A.; REINERT, D.J. \& REICHERT, J.M. Variabilidade temporal da resistência à penetração de um Latossolo Argiloso sob semeadura direta com rotação de culturas. R. Bras. Ci. Solo, 28:477-484, 2004.

GUBIANI, P.I.; REINERT, D.J. \& REICHERT, J.M. Método alternativo para a determinação da densidade de partículas do solo - exatidão, precisão e tempo de processamento. Ci. Rural, 36:664-668, 2006.

HERLIHY, M. \& McCARTHY, J. Association of soil test phosphorus with phosphorus fractions and adsorption characteristics. Nutr. Cycl. Agroecosyst., 75:79-90, 2006.

KLEIN, V.A.; VIEIRA, M.L.; DURIGON, F.F.; MASSING, J.P. \& FÁVERO, F. Porosidade de aeração de um Latossolo Vermelho e rendimento de trigo em plantio direto escarificado. Ci. Rural, 38:365-371, 2008.

LIMA, C.L.R.; SILVA, A.P.; IMHOFF, S.; LIMA, H.V. \& LEÃO, T.P. Heterogeneidade da compactação de um Latossolo Vermelho-Amarelo sob pomar de laranja. R. Bras. Ci. Solo, 28:409-414, 2004.

LUCIANO, R.V. Variabilidade espacial e temporal de atributos do solo e relação com a qualidade da uva para vinificação no Planalto Catarinense. Lages, Universidade do Estado de Santa Catarina, 2012. 161p. (Tese de Doutorado)

NESMITH, D.S. Soil compaction in double cropped wheat and soybean on Ultissol. Soil Sci. Soc. Am. J., 51:183-186, 1987.

MEROTTO JUNIOR, A. \& MUNDSTOCK, C.M. Wheat root growth as affected by soil strength. R. Bras. Ci. Solo, 23:197-202, 1999.
MIALHE, L.G. Máquinas motoras na agricultura. São Paulo, Universidade de São Paulo, 1980. v.2. 367p.

PANDOLFO, C.; BRAGA, H.J.; SILVA JÚNIOR, V.P.; MASSIGNAM, A.M.; PEREIRA, E.S. \& THOMÉ, V.M.R. Atlas climático digital do Estado de Santa Catarina. Florianópolis, EPAGRI, 2002. CD-ROM

PORTUGAL, A.F.; COSTA, O.D.A.; COSTA, L.M. \& SANTOS, B.C.M. Atributos químicos e físicos de um Cambissolo Háplico Tb distrófico sob diferentes usos na Zona da Mata Mineira. R. Bras. Ci. Solo, 32:249-258, 2008.

Portugal, A.F.; Costa, O.D.V. \& CostA, L.M. Propriedades físicas e químicas do solo em áreas com sistemas produtivos e mata na região da Zona da Mata mineira. R. Bras. Ci. Solo, 34:575-585, 2010.

PROTAS, J.F.S. Uvas viníferas para processamento em regiões de clima temperado. Bento Gonçalves, Embrapa-CNPUV, 2003. (Sistema de Produção, 4)

REICHERT, J.M.; REINERT, D.J. \& BRAIDA, J.A. Qualidade dos solos e sustentabilidade de sistemas agrícolas. R. Ci. Amb., 27:29-48, 2003.

REICHERT, J.M.; SUZUKI, L.E.A.S. \& REINERT, D.J. Compactação do solo em sistemas agropecuários e florestais: Identificação, efeitos, limites críticos e mitigação. In: CERETTA, C.A.; SILVA, L.S. \& REICHERT, J.M., eds. Tópicos em ciência solo. Viçosa, MG, Sociedade Brasileira de Ciência do Solo, 2007. v.5, p.49-134.

REINERT, D.J. \& REICHERT, J.M. Propriedades físicas do solo. Santa Maria, Universidade Federal Santa Maria, 2006. 18p.

ROSA, J.D.; MAFRA, A.L.; NOHATTO, M.; FERREIRA, E.Z.; OLIVEIRA, O.L.P.; MIQUELUTTI, D.J.; CASSOL, P.C. \& MEDEIROS, J.C. Atributos químicos do solo e produtividade de videiras alterados pelo manejo de coberturas verdes na Serra Gaúcha. R. Bras. Ci. Solo, 33:179-187, 2009.

SALTON, J.C.; MIELNICZUK, J.; BAYER, C.; BOENI, M.; CONCEIÇÃO, P.C.; FABRÍCIO, A.C.; MACEDO, M.C.M. \& BROCH, D.L. Agregação e estabilidade de agregados do solo em sistemas agropecuários em Mato Grosso do Sul. R. Bras. Ci. Solo, 32:11-21, 2008.

SANTOS, G.A.S. Fundamentos da matéria orgânica do solo: Ecossistemas tropicais \& subtropicais. In: SANTOS, G.A.; SILVA, L.S.; CANELlAS, L.P. \& CAMARGO, F.A.O., eds. Dinâmica e função da matéria orgânica. 2.ed. Porto Alegre, Metrópole, 2008. p.7-16.

SEIXAS, F. \& SOUZA, C.R. Avaliação e efeito da compactação do solo, devido à frequência de tráfego, na produção de madeira de eucalipto. R. Árvore, 31:1047-1052, 2007.

SILVA, M.A.S.; MAFRA, A.L.; ALBUQUERQUE, J.A.; ROSA, J.D.; BAYER, C. \& MIELNICZUK, J. Propriedades físicas e teor de carbono orgânico de um Argissolo Vermelho sob distintos sistemas de uso e manejo. R. Bras. Ci. Solo, 30:327-337, 2006. 
SNEDECOR, W. \& COCHRAN, W.G. Statistical methods. 8.ed. Ames, Iowa State University Press, 1989. 502p.

SUZUKI, L.E.A.S. Compactação do solo e sua influência nas propriedades físicas. Santa Maria, Universidade Federal de Santa Maria, 2005. 149p. (Dissertação de Mestrado)

TAYLOR, H.M.; ROBERTSON, G.M. \& PARKER, J.J. Soil strength root penetration relations for medium to coarse textured soil materials. Soil Sci., 102:18-22, 1966.

TEDESCO, M.J.; GIANELLO, C.; BISSANI, C.; BOHNEN, H. \& VOLKWEISS, S.J. Análise de solo, plantas e outros materiais. 2.ed. Porto Alegre, Universidade Federal do Rio Grande do Sul, 1995. 174p. (Boletim Técnico, 5)

TISDALL, J.M. \& OADES, J.M. Organic matter and waterstable aggregates in soils. J. Soil Sci., 33:141-164, 1982. van DIJCK, S.J.E. \& van ASCH, Th.W.J. Compaction of loamy soils due to tractor traffic in vineyards and orchards and its effect on infiltration in southern France. Soil Till. Res.; 63:141-153, 2002.

van LIER, J.Q. Oxigenação do sistema radicular: Uma abordagem física. R. Bras.Ci. Solo, 25:233-238, 2001.

VEIGA, M. Metodologias para coleta de amostras e análises físicas do solo. Florianópolis, EPAGRI, 2011. 52p. (Boletim Técnico, 156)

VOCANSON A.; ROGER-ESTRADE J.; BOIZARD H. \& JEUFFROY M.H. Effects of soil structure on root development of pea (Pisum sativum L.) according to the sowing date and the cultivar. Plant Soil, 281:121-135, 2006.

XU, X.; NIEBER, J.L. \& GUPTA, S.C. Compaction effects on the gas diffusion coefficients in soils. Soil Sci. Soc. Am. J., 56:1743-1750, 1992. 